\title{
Interaction between the Plant Growth Retardant Cycocel and the Plant Growth Stimulant Indol Acetic Acid (IAA)
}

\author{
A. Kabarity and S. Khodary \\ Botany Department, Faculty of Science, Kuwait University, Kuwait
}

Received April 5, 1973

Since 2-chloroethyl trimethyl ammonium chloride (cycocel) acts as a retardant for the growth of the roots and there are substances like indol acetic acid which stimulate the growth we set out to determine whether there is any interaction between cycocel and indol acetic acid in the effects they produce on mitosis. The cytological effects on cycocel and indol acetic acid separately were already examined (Kabarity and Khodary $1974 \mathrm{a}, \mathrm{b}, \mathrm{c}$ ).

In the present investigation the cytological behaviour of Vicia faba root tips treated with both together was studied.

\section{Materials and methods}

The experimental plant used in this investigation was broad bean (Vicia faba var. Kobrosy). Pure strains of the above mentioned plant was obtained from Egyptian Ministry of Agriculture. The growth retarding chemical cycocel (CCC) and indol acetic acid (IAA) were obtained from the department of cotton research, Ministry of Agriculture of Arab Republic of Egypt.

Broad beans (Vicia faba var. Kobrosy) were soaked in tap water for 24 hours, and then planted in pots, seeds were let to germinate 10 days, and after the roots (lateral roots) were 4-6 cm long they were placed in solutions which contained the test substances for the time given in text. The root tips were then fixed in Carnoy (3: 1 absolute alcohol; glacial acetic acid) for 24 hours. The concentrations of the test substances were expressed in the tables in terms of part per million (ppm). At least 20 root tips from each incubation were fixed and prepared by using Feulgen's squash method.

\section{Results}

1. Interaction between different concentrations of IAA and 12,000 ppm CCC for 4 hours treatment

The difference between the effects produced by IAA and CCC on mitosis makes it easy to determine whether any interaction occurs between them when they are used together to treat roots.

After 4 hours combined treatment of IAA and $12,000 \mathrm{ppm} \mathrm{CCC}$, there was a depression in mitotic indices in all of the applied concentrations. Fig. 2 represented 
the mitotic analysis of $800,600,400,200$ and $100 \mathrm{ppm}$ IAA, $12,000 \mathrm{ppm} \mathrm{CCC}$ and the above mentioned concentrations of IAA and CCC together. Concentration $400 \mathrm{ppm}$ IAA with $12,000 \mathrm{ppm} \mathrm{CCC}$ showed the highest mitotic index (3.2) decreased gradually till reached (2.1) in the weakest solution. The high value of MI (3.2) was due to the accumulation of metaphase stage as its frequency reached (95.6) and there was an inhibition in both prophases and anaphases. Normal metaphases and anaphases were absent in the last two concentrations although it was found by using IAA alone (Table 1 and 2). The cytological effect of (800 or 600 IAA + $12,000 \mathrm{ppm}$ CCC) was characterised by stickiness in all phases examined, meanwhile c-metaphases were represented in the other concentrations (400 ppm IAA+ $12,000 \mathrm{ppm} \mathrm{CCC}),(200 \mathrm{ppm}$ IAA $+12,000 \mathrm{ppm} \mathrm{CCC}),(100 \mathrm{ppm} \mathrm{IAA}+12,000 \mathrm{ppm}$ $\mathrm{CCC}$.

Table 1. Numbers of cells in interphase and in mitosis in cells of Vicia faba roots treated with different conc. of IAA

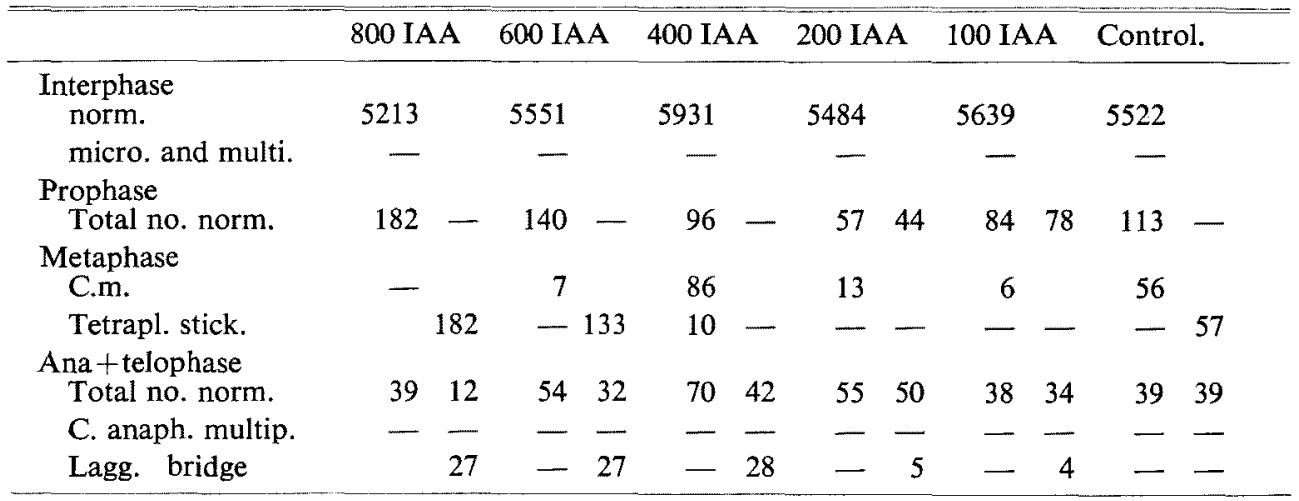

2. Interaction between different concentrations of IAA and 12,000 ppm CCC for 4 hours treatment followed by 1 hour recovery

After 1 hour recovery mitotic index had been risen in all concentrations used. MI of highest and lowest concentration was similar (5.8 and 5.7) which showed an increase than those in control value (3.7) (Fig. 2).

Concerning the abnormalities found in the divided cells after the combined treatment and fixed 1 hour later, the abnormal stickey metaphase figures first seen after 4 hours treatment in the first 2 concentrations were changed to c-metaphases. Tetraploid cells were often observed in cells treated with IAA and CCC and fixed 1 hour later. 33 tetraploid cells per 248 divided cells were found in concentration (400 ppm IAA + 12,000 ppm CCC). Also this concentration showed a high number of multipolar anaphase 48 cells among 248 divided cells. This number of multipolar anaphases and tetraploid cells decreased reaching 39,17 respectively in 100 ppm IAA $+12,000$ ppm CCC (Table 2).

3. Interaction between different concentrations of IAA and 12,000 ppm CCC for 4 hours treatment followed by 2 hours recovery

After 2 hours recovery to these combined treatment, MI fell in all of the applied concentrations except the highest which showed an increase in MI from 5.8 


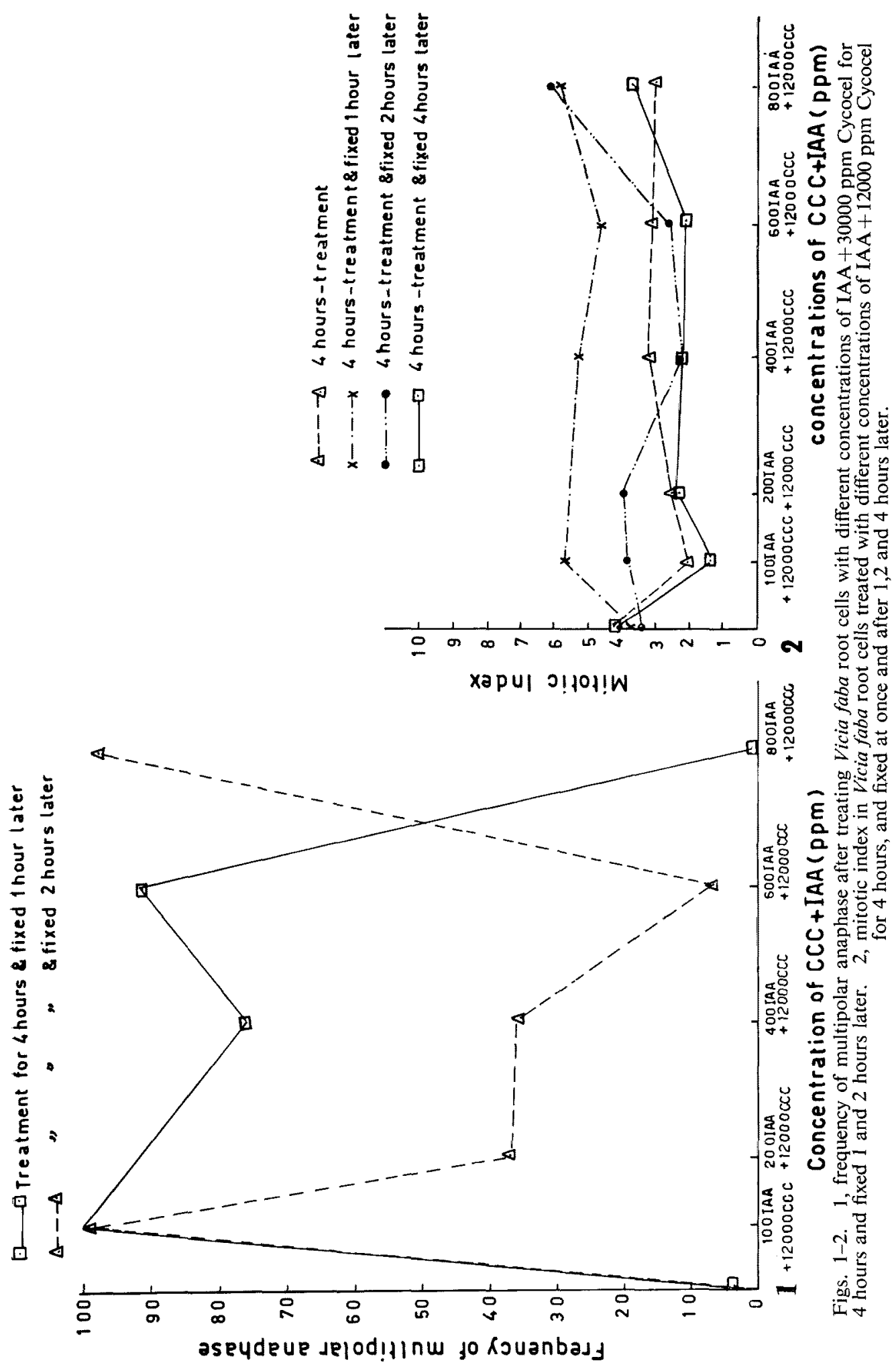


Table 2. Numbers of cells in interphase and in mitosis in cells of Vicia faba roots treated with different conc. of IAA and $12000 \mathrm{CCC}$ in combined treatments for $4 \mathrm{~h}, 4 \mathrm{~h}$ and fixed $1 \mathrm{~h}$ later, $2 \mathrm{~h}$ later, $4 \mathrm{~h}$ later

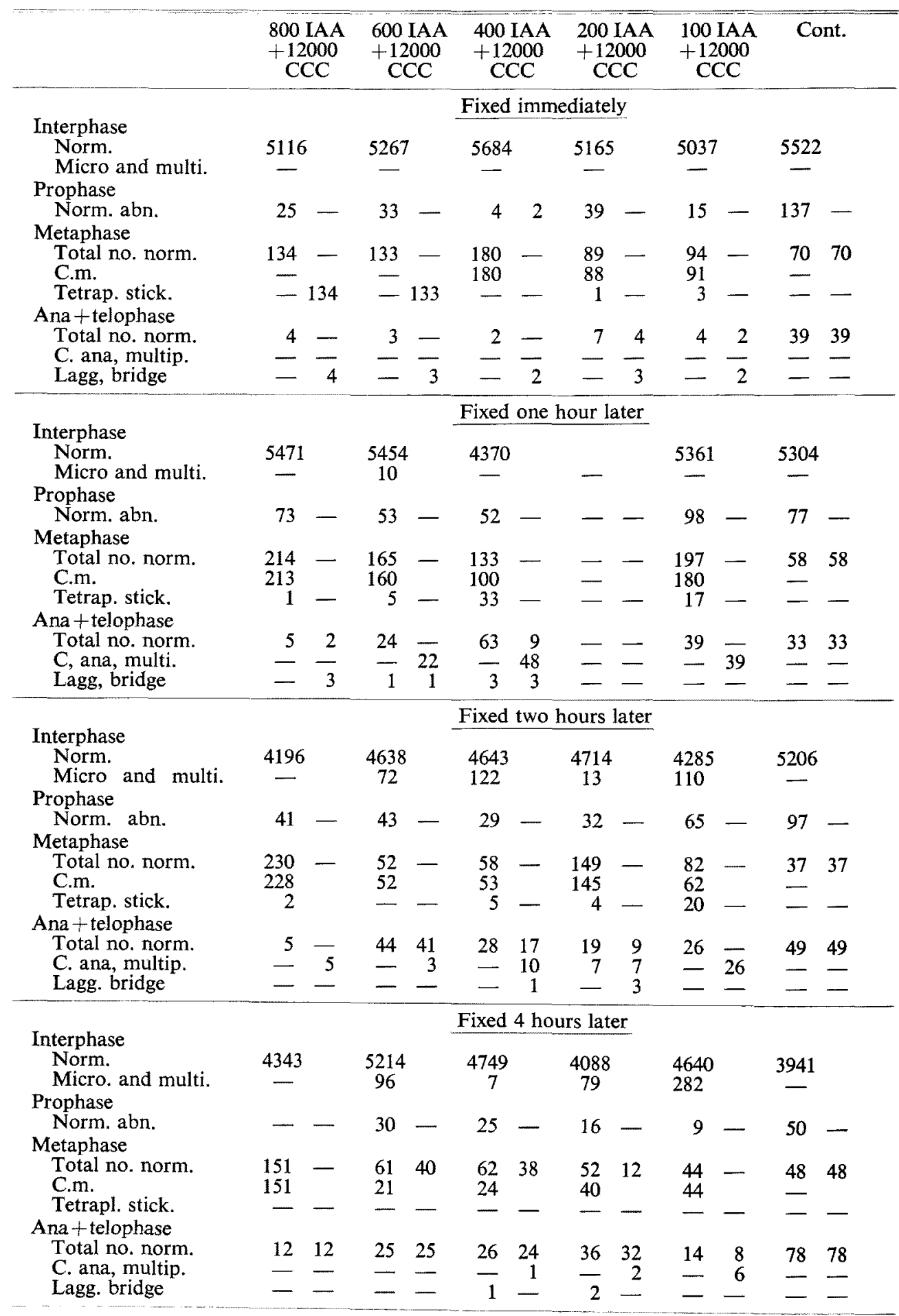




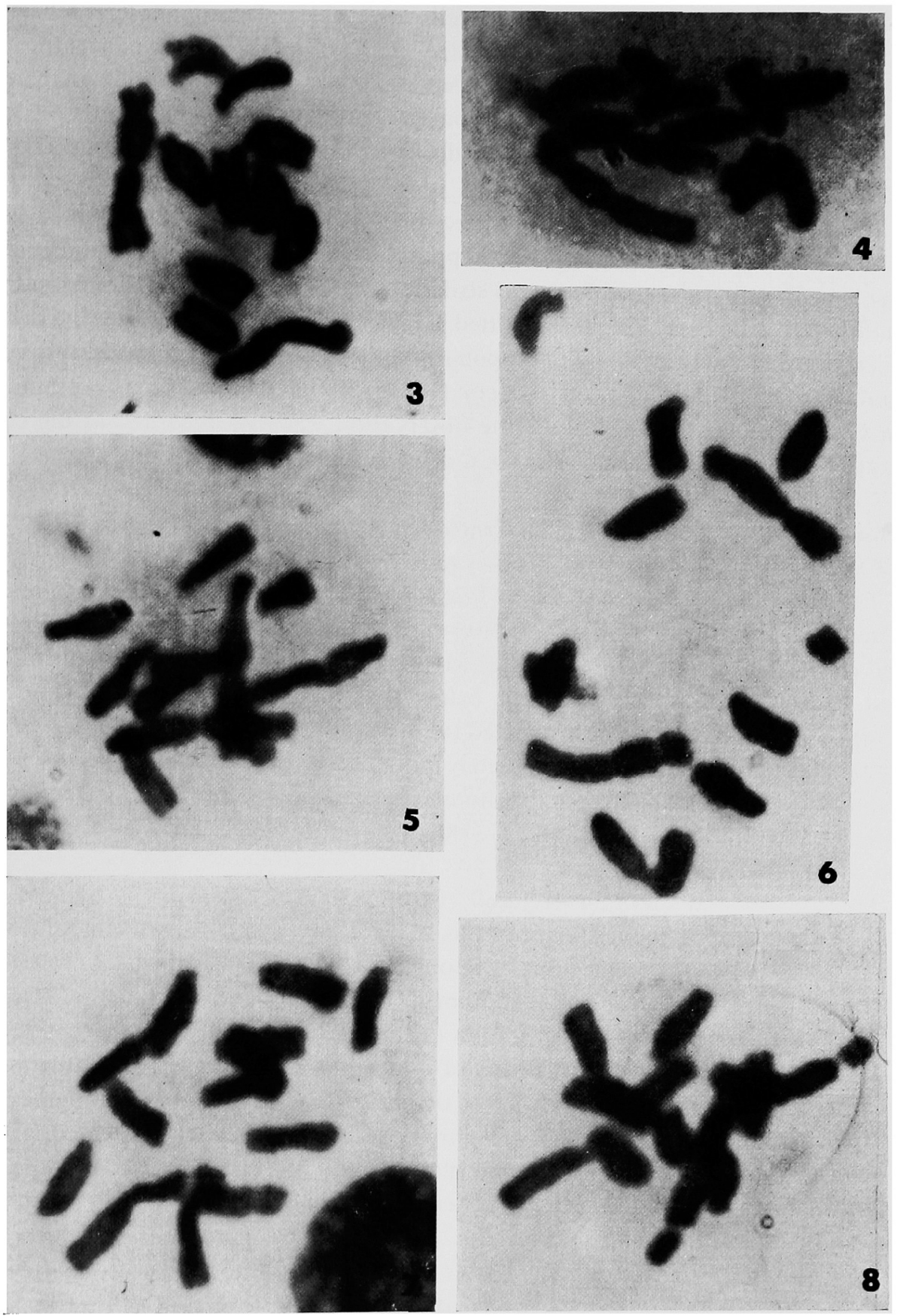

Figs. 3-8. 3, c-metaphase in Vicia faba roots after treatment with 800 IAA $+12,000 \mathrm{CCC}$ ppm for 4 hours. 4, c-metaphase after the treatment with $(200 \mathrm{IAA}+12,000 \mathrm{CCC}) \mathrm{ppm}$ for 4 hours. 5 , c-metaphase after the treatment with $(100 \mathrm{IAA}+12,000 \mathrm{CCC}) \mathrm{ppm}$ for 4 hours. 6, c-metaphase after the treatment with (800 IAA $+12,000 \mathrm{CCC}) \mathrm{ppm}$ for 4 hours and fixed one hour later. 7, c-metaphase in Vicia faba roots with $(600 \mathrm{IAA}+12,000 \mathrm{CCC}) \mathrm{ppm}$ for 4 hours and fixed one hour later. 8, abnormal metaphase after treatment with $(800 \mathrm{IAA}+12,000 \mathrm{CCC}) \mathrm{ppm}$ for 4 hours and fixed 2 hours later. 
to 6.1 (Fig. 2). Number of tetraploid cells and multipolar anaphase reached 20 and 26 respectively among the total divided cells 173 in the lowest concentration, then this number decreased as the concentration increased. Normal anaphases started to appear earlier in concentration $(600 \mathrm{ppm} \mathrm{IAA}+12,000 \mathrm{ppm} \mathrm{CCC})$ as represented by 41 cells showing gradual decrease towards the lower concentration (Table 2).

After 1 and 2 hours recovery to the roots of Vicia faba previously treated with different concentrations of IAA $+12,000 \mathrm{ppm}$ CCC) for 4 hours, the number and percentage of multipolar anaphase was strikingly high (Table 2), thus the percentage of multipolar anaphase had been plotted against concentrations (Fig. 1). It can be seen that high percentage of multipolar anaphase was found at the lowest concentration after 1 and 2 hours recovery $(100 \%)$ as all the anaphases was found from the multipolar type and the same observation was also recorded at the concentration of $800 \mathrm{IAA}+12,000 \mathrm{ppm} \mathrm{CCC}$ after 2 hours recovery (Table 2).

\section{Interaction between different concentration of IAA and 12,000 ppm CCC for} 4 hours treatment followed by 4 hours recovery

The trend in the fall in MI that is first seen after 2 hours recovery continues in the followed experiment (4 hours recovery). The highest mitotic index (3.6) was found in the highest concentration and MI of lowest value (1.3) was found in the lowest concentration which remained below that of control value (4.2) (Fig. 2). The high value of $\mathrm{MI}(3.6)$ was attributed to the high frequency of metaphases $(92 \%)$ although it is accompanied with completely inhibition of the prophase stage. Normal metaphases started to appear after (4 hours recovery) in the root cells treated with different concentrations of IAA and $12,000 \mathrm{ppm}$ and normal anaphases were found in all concentrations.

Micronuclei and multinucleate cells which previously seen after 2 hours recovery with this combined treatment was also observed after treatment of Vicia faba root cells with different concentrations of IAA $+12,000 \mathrm{ppm}$ CCC followed by 4 hours recovery, reaching a maximum of 282 micro- and multinucleated cells per 5,000 cells at the lowest concentration (Table 2).

Figs. 3-8 represent different forms of c-metaphases after combined treatment with different concentrations of IAA $+12,000 \mathrm{ppm} \mathrm{CCC}$ for 4 hours treatment and for different periods of recovery. 12 chromosomes were clearly observed. The chromosomes do not form a metaphase plate. They are distributed at random all over the cell and each chromosome divides into two distinct chromatids which are attached only at their centromere. Fig. 6 represents c-metaphase in which the chromosomes were highly contracted after 1 hour recovery to the root cells treated with $(800 \mathrm{IAA}+12,000 \mathrm{ppm} \mathrm{CCC})$. Treatment of Vicia faba root cells with IAA $+12,000 \mathrm{ppm}$ CCC and fixed few hours later showed different types of abnormal anaphases. Multipolar anaphases were very numerous, the number of poles ranging from three poles to several poles (Figs. 11, 12, 13, and 14). Chromosome bridge

$+12,000 \mathrm{CCC}$ ) ppm for $4 \mathrm{hrs}$ and fixed $1 \mathrm{hr}$ later. 15, lagging of chromosome after treatment with $400 \mathrm{IAA}+12,000 \mathrm{CCC}$ ppm for $4 \mathrm{hrs}$ and fixed $2 \mathrm{hrs}$ later. 16, multinucleated cell after treatment with $400 \mathrm{IAA}+12,000 \mathrm{CCC}$ ppm for $4 \mathrm{hrs}$ and fixed $2 \mathrm{hrs}$ later. 

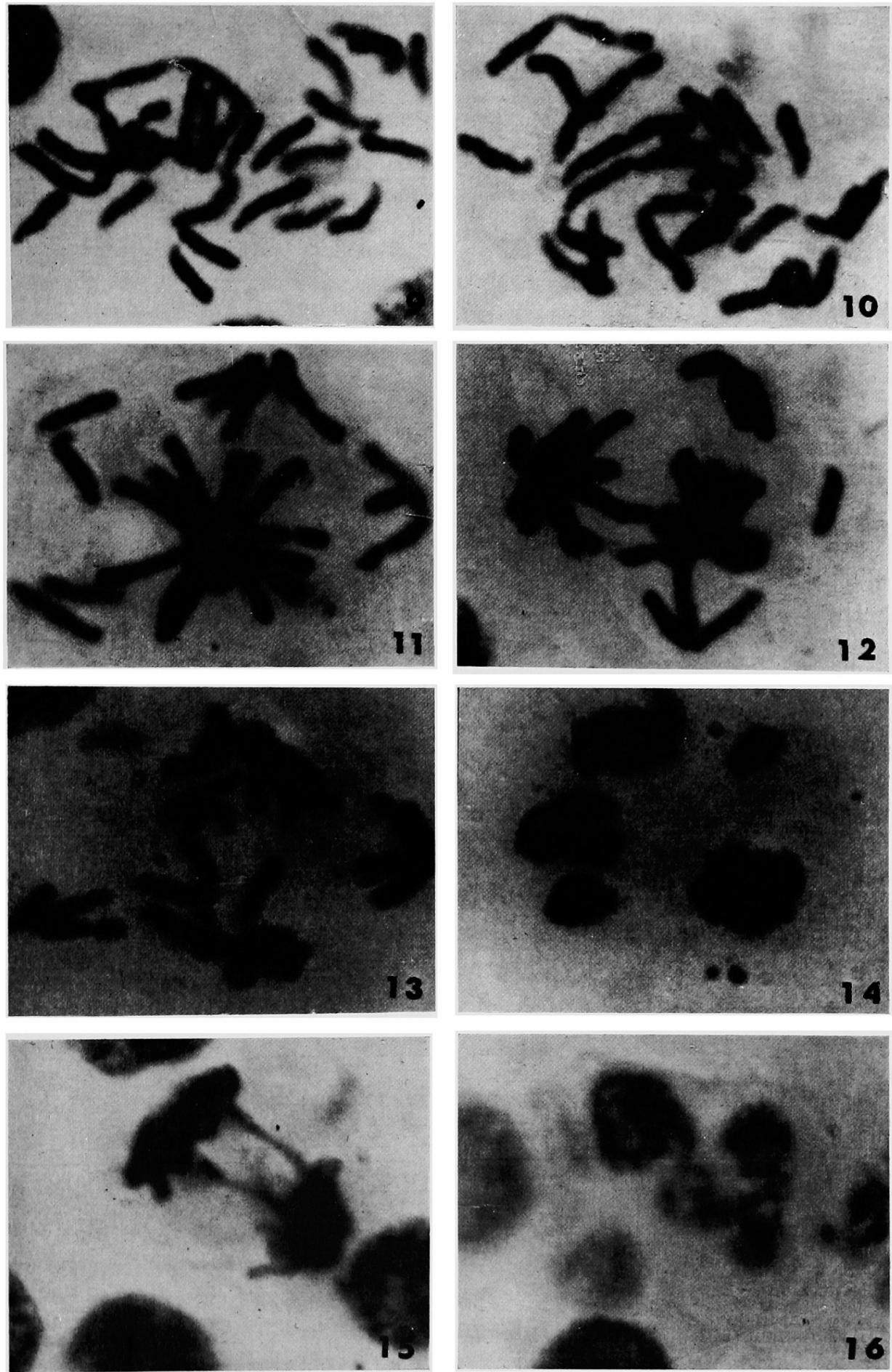

Figs. 9-16. 9 and 10, doubling of chromosome number (c-anaphases) after treatment with (IAA $+12,000$ CCC) ppm for 4 hours (Fig. 11), the same treatment but fixed one hour later (Fig. 12). 11 and 12 , multipolar anaphases after treatment with $(400 \mathrm{IAA}+12,000 \mathrm{CCC}) \mathrm{ppm}$ for 4 hours treatment. 13, multipolar anaphase after treatment with $(800 \mathrm{IAA}+12,000 \mathrm{CCC}) \mathrm{ppm}$ for 4 hours treatment and fixed one hour later. 14, multipolar telophase after treatment with (400 IAA 
Table 3. Numbers of cells in interphase and in mitosis in cells of Vicia faba roots treated with (different concentrations of IAA) and $4000 \mathrm{ppm} \mathrm{CCC} \mathrm{in} \mathrm{combined}$ treatments for $4 \mathrm{~h}, 4 \mathrm{~h}$ and fixed $1 \mathrm{~h}$ later, $2 \mathrm{~h}$ later, $4 \mathrm{~h}$ later

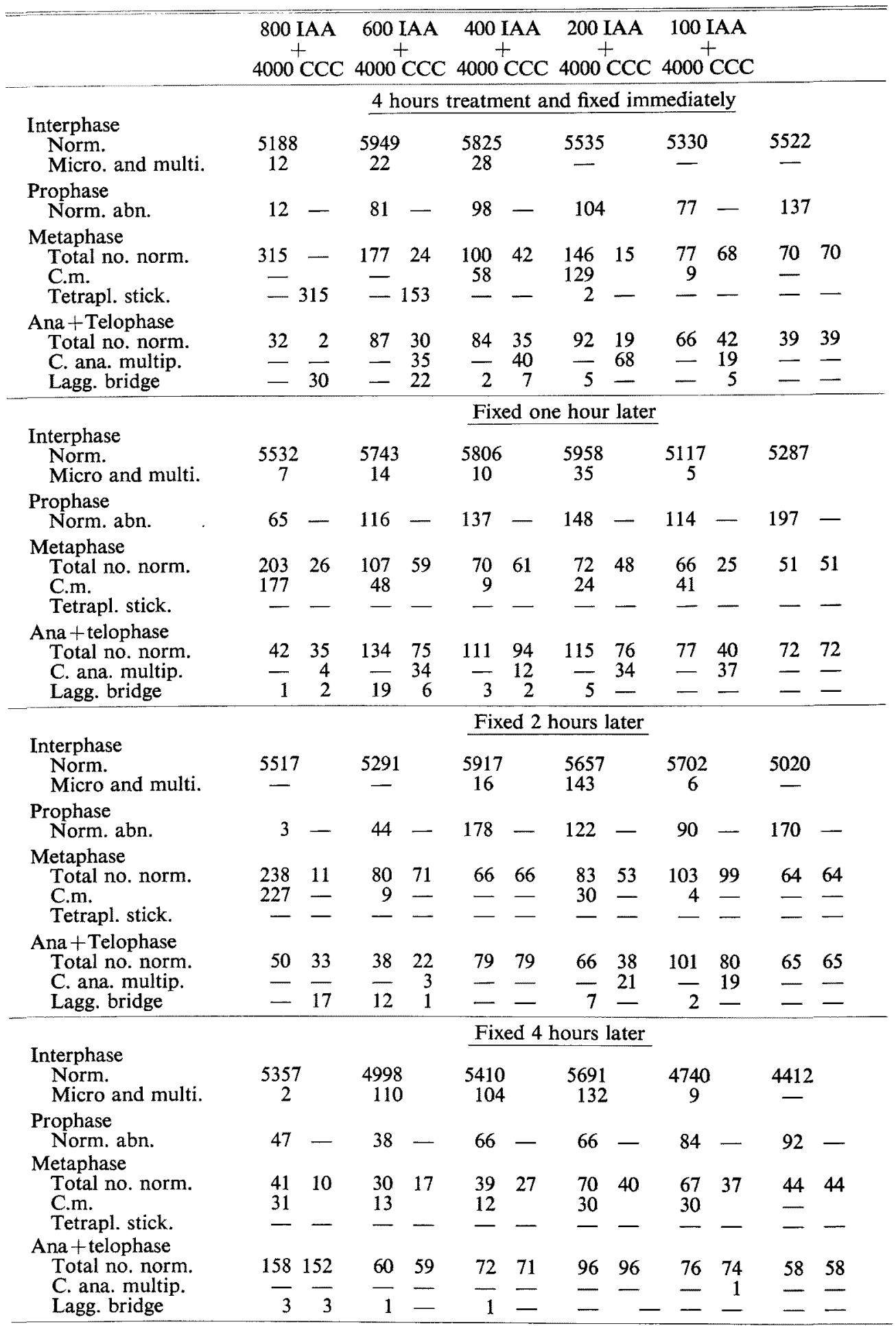


was also observed in few phases, represented by Fig. 15. Multinucleated cells and micronuclei were represented in Fig. 16.

5. Interaction between different concentrations of IAA and 4,000 ppm CCC for

\section{4 hours treatment}

Concerning MI, it is clear that its value was higher in roots treated with 4,000 ppm CCC, alone, or with IAA than in roots treated only with IAA (Fig. 17). According to the normal and abnormal phases, treatment of Vicia faba root cells with $4,000 \mathrm{ppm}$ CCC resulted in the generation of c-metaphases (all metaphases were of abnormal type). Treatment with IAA alone showed no normal metaphases, treatment of Vicia faba root cells with $4,000 \mathrm{ppm} \mathrm{CCC} \mathrm{resulted} \mathrm{in} \mathrm{the} \mathrm{generation} \mathrm{of}$ c-metaphases (all metaphases were of abnormal type). Treatment with IAA alone showed no normal metaphases at 600 and $400 \mathrm{ppm} \mathrm{CCC}$. But, in the present experiment, addition of $4,000 \mathrm{ppm} \mathrm{CCC} \mathrm{to} \mathrm{different} \mathrm{concentrations} \mathrm{of} \mathrm{IAA,} \mathrm{specially}$ at the previously mentioned two concentrations of IAA (600 and $400 \mathrm{ppm}$ ) resulted in the generation of normal metaphases which attained the highest number of 42 cells at concentration of ( $400 \mathrm{ppm} \mathrm{IAA}+4,000 \mathrm{ppm} \mathrm{CCC})$. This observation was not met on using either IAA or CCC alone in the previous mentioned concentrations (Kabarity and Khodary 1974a,c).

Finally we come to the conclusion: using combined treatment of (600 or 400 ppm IAA $+4,000 \mathrm{ppm}$ CCC) led to an antagonistic effect. And also addition of $\mathrm{CCC}$ at this concentration to IAA at different concentrations induced an increase in the abnormal anaphases as well as induced multipolar anaphase (Table 3).

6. Interaction between different concentrations of IAA and 4,000 ppm CCC for 4 hours treatment followed by 1 hour recovery

After 1 hour recovery to the root cells previously treated with different concentrations of (IAA $+4,000 \mathrm{ppm}$ CCC), the MI showed a slight increase at all concentrations, except at the highest concentration which showed a decrease from 6.5 to 5.4 (Table 3). The number of normal phases started to appear earlier at the first concentration after 1 hour recovery, i.e. the roots do a recover. Number of normal phases which previously found at 4 hour treatment showing an increase after 1 hour recovery and increased by 2 hours and 4 hours recovery. Concentration $200 \mathrm{ppm} \mathrm{IAA}+4,000 \mathrm{ppm} \mathrm{CCC}$ represented always the highest number of micronuclei and multinucleate cells.

7. Interaction between different concentrations of IAA and 4,000 ppm CCC for 4 hours treatment followed by 2 hours recovery

After 2 hours recovery, MI began to decrease and continued this decrease by further recovery for 4 hours. This decrease is due to the gradual fall in the number of total divided cells. The number of normal cells showed an increase and that of abnormal cells was decreased as the intervals of the recovery increased.

8. Interaction between different concentrations of IAA and 4,000 ppm for 4 hours treatment followed by 4 hours recovery 


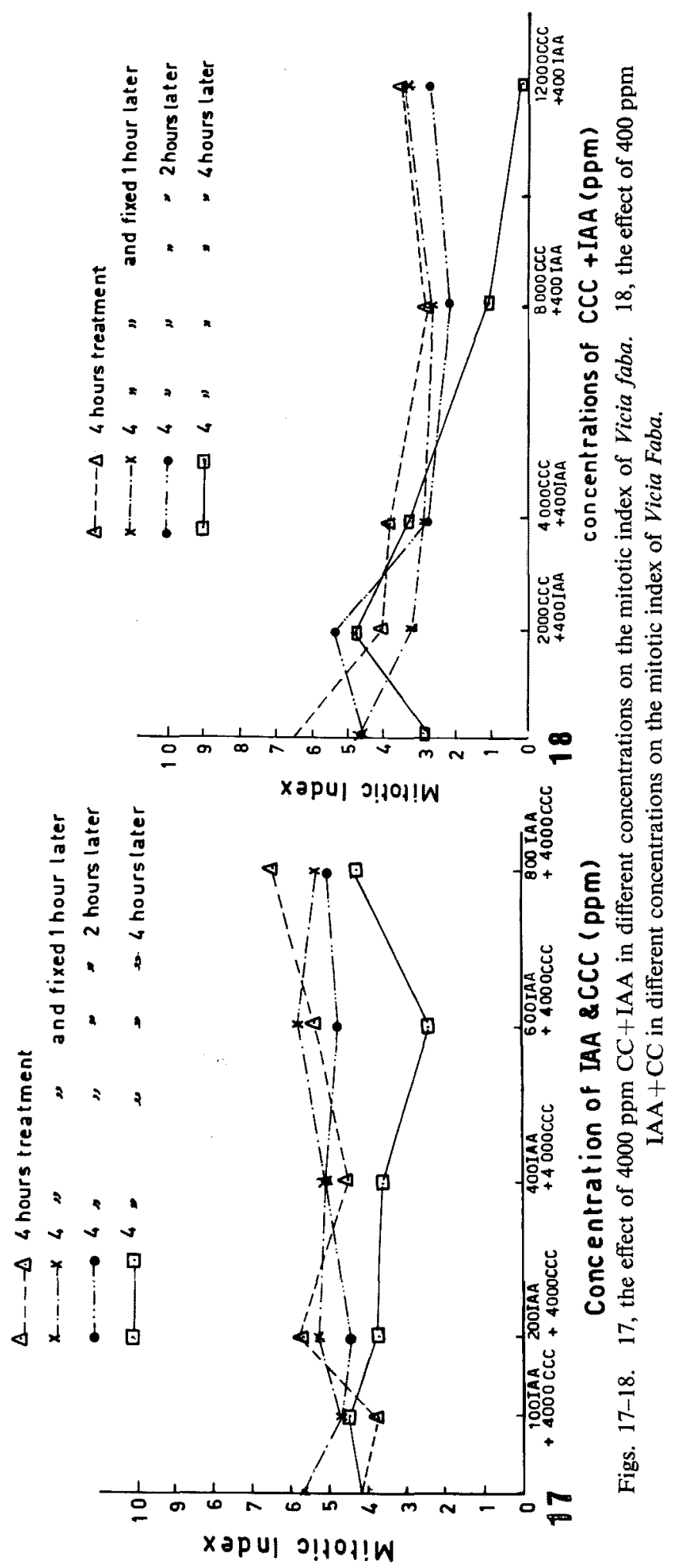


After 4 hours recovery to the root cells of Vicia faba treated with this combined treatment, the highest frequency was reached with anaphase as compared with the other phases at all concentrations applied. The maximum frequency of anaphase $(68.2 \%)$ was found at the first concentration, then decreased gradually as the concentration decreased till $33.4 \%$ in the weakest solution (Table 3 ).

\section{Interaction between different concentrations of CCC and 400 ppm after 4 hours treatment}

In order to confirm the previously mentioned conclusion: "There is an antagonistic effect between concentration of 4,000 ppm CCC and $400 \mathrm{ppm} \mathrm{IAA",} \mathrm{this} \mathrm{ex-}$ periment has been carried out: concentration of $400 \mathrm{ppm}$ IAA was added to each of different concentrations of CCC $(12,000,8,000,4,000$ and $5,000 \mathrm{ppm}$ CCC). The antagonistic effect was observed 4 hours after the experiment began at the same concentration $(4,000 \mathrm{ppm} \mathrm{CCC}+400 \mathrm{ppm}$ IAA) just as was expected, and could be detected by the appearance of the same number of normal cells in metaphase stage beside that of c-metaphase i.e. 55 normal metaphase and $49 \mathrm{c}$-metaphase. This number of either normal metaphase and c-metaphase is similar to those found in the previous experiment at the same concentration (Tables 3 and 5).

Table 4. Numbers of cells in interphase and in mitosis in cells of Vicia faba roots treated with different conc. of CCC

\begin{tabular}{|c|c|c|c|c|c|c|c|c|c|c|c|}
\hline & $12000 \mathrm{CCC}$ & \multicolumn{2}{|c|}{$8000 \mathrm{CCC}$} & \multicolumn{2}{|c|}{$4000 \mathrm{CCC}$} & \multicolumn{2}{|c|}{$2000 \mathrm{CCC}$} & \multicolumn{2}{|c|}{400 IAA } & \multicolumn{2}{|c|}{ Contro } \\
\hline $\begin{array}{l}\text { Interphase } \\
\text { Norm. }\end{array}$ & 5280 & 5250 & & 5689 & & 5010 & & 5931 & & 5014 & \\
\hline Micro. and multi. & - & - & & - & & - & & - & & - & \\
\hline \multicolumn{12}{|l|}{ Prophase } \\
\hline Norm. abn. & 158 & 176 & - & 107 & - & 87 & - & 131 & 9 & 176 & - \\
\hline \multicolumn{12}{|l|}{ Metaphase } \\
\hline Total no. norm. & $134-$ & 83 & - & 120 & - & 46 & 30 & 96 & - & 80 & 80 \\
\hline C.m. & - & 27 & & 120 & & 16 & & 86 & & - & \\
\hline Tetrapl, stick. & -134 & - & 56 & - & - & - & - & 10 & - & - & - \\
\hline \multicolumn{12}{|l|}{ Ana + telephase } \\
\hline Total no. norm. & - & - & - & 42 & 14 & 35 & 20 & 42 & - & 86 & - \\
\hline C. ana. multip. & - & - & - & - & 22 & - & 6 & 一 & - & - & - \\
\hline Lagg. bridge & $-\ldots$ & - & - & - & 6 & 2 & - & - & 28 & - & - \\
\hline
\end{tabular}

Normal metaphase was also found by using $(20,000 \mathrm{ppm} \mathrm{CCC}+400 \mathrm{ppm}$ IAA) but in a less number, (11 cells per total divided cells). This observation was not shown in those concentrations of either CCC or IAA.

Anaphases of high number (41) were observed at the lowest concentration, then fell gradually till reached (6) at the highest one.

There was a depression in the mitotic index of root cells treated with different concentrations of CCC due to the addition of IAA (Fig. 18). The highest value of MI (4) was found at the lowest concentration (2,000 ppm CCC $+400 \mathrm{ppm}$ IAA).

Metaphase with high frequency of $80 \%$ was found at the highest concentration after 4 hours treatment, then decreased gradually to 70.7, 45.6 till reached 30.2 at the lowest concentration used. This lowest concentration also possessed the highest frequency of prophases $51.0 \%$. Frequency of prophase and anaphase was 
Table 5. Numbers of cells in interphase and in mitosis in cells of Vicia faba roots treated with different concs. of CCC and 400 IAA for 4 hours anf fixed immediately and after $1 \mathrm{~h}, 2 \mathrm{~h}, 4 \mathrm{~h}$ later

\begin{tabular}{|c|c|c|c|c|c|c|c|c|c|c|}
\hline \multirow{2}{*}{ Interphase } & \multicolumn{2}{|c|}{$\begin{array}{c}12000 \mathrm{CCC} \\
+ \\
400 \mathrm{IAA}\end{array}$} & \multicolumn{2}{|c|}{$\begin{array}{c}8000 \mathrm{CCC} \\
+ \\
400 \text { IAA }\end{array}$} & \multicolumn{2}{|c|}{$\begin{array}{c}4000 \mathrm{CCC} \\
+ \\
400 \mathrm{IAA}\end{array}$} & \multicolumn{2}{|c|}{$\begin{array}{c}2000 \mathrm{CCC} \\
+ \\
400 \text { IAA }\end{array}$} & \multicolumn{2}{|c|}{ Control } \\
\hline & \multicolumn{10}{|c|}{ Fixed immediately } \\
\hline $\begin{array}{l}\text { Normase } \\
\text { Norm. }\end{array}$ & \multicolumn{2}{|l|}{5075} & \multicolumn{2}{|l|}{5041} & \multicolumn{2}{|l|}{5531} & \multicolumn{2}{|l|}{5460} & \multicolumn{2}{|l|}{5014} \\
\hline Micro. and multi. & - & & - & & - & & - & - & - & \\
\hline \multicolumn{11}{|l|}{ Prophase } \\
\hline Norm. abn. & 31 & - & 23 & - & 103 & - & 118 & - & 176 & - \\
\hline \multicolumn{11}{|l|}{ Metaphase } \\
\hline Total no. norm. & 146 & - & 104 & 11 & 104 & 55 & 69 & 44 & 80 & 80 \\
\hline C.m. & 143 & - & 92 & - & 49 & - & 25 & - & - & - \\
\hline Tetrapl. stick. & 3 & - & 1 & - & - & - & - & - & - & - \\
\hline \multicolumn{11}{|l|}{ Ana + telophase } \\
\hline Total no. norm. & 6 & - & 20 & 12 & 21 & 20 & 41 & 38 & 86 & 86 \\
\hline C. ana. multip. & - & 1 & - & 6 & - & - & - & - & - & - \\
\hline Lagg. bridge & 4 & 1 & 1 & 1 & - & 1 & 1 & 2 & - & - \\
\hline & \multicolumn{10}{|c|}{1 hour later } \\
\hline Interphase & & & & & & & & & & \\
\hline Norm. & 5450 & & 5456 & & 5547 & & 5563 & & 5711 & \\
\hline Micro. and multi. & - & & - & & - & & - & & - & \\
\hline Prophase & & & & & & & & & & \\
\hline Norm. abn. & 31 & - & 33 & - & 29 & - & 75 & - & 137 & - \\
\hline Metaphase & & & & & & & & & & \\
\hline Total no. norm. & 146 & 4 & 45 & 4 & 101 & 55 & 73 & 59 & 71 & 71 \\
\hline C.m. & 137 & - & 39 & - & 44 & - & 13 & - & - & - \\
\hline Tetrapl. stick. & 5 & - & 2 & - & 2 & - & 1 & - & - & - \\
\hline Ana + telophase & & & & & & & & & & \\
\hline Total no. norm. & 18 & 12 & 37 & 24 & 32 & 18 & 36 & 31 & 35 & 35 \\
\hline C. ana. multip. & - & 6 & 2 & 5 & 1 & 3 & - & 1 & - & - \\
\hline Lagg. bridge & - & - & $\overline{3}$ & 3 & 5 & 5 & 1 & 3 & - & - \\
\hline & & & & & 2 hours & later & & & & \\
\hline Interphase & & & & & & & & & & \\
\hline Norm. & 5027 & & 5991 & & 5356 & & 5230 & & 5409 & \\
\hline Micro and multip. & & & - & & & & . & & - & \\
\hline Prophase & & & & & & & & & & \\
\hline Norm. abn. & 18 & - & 32 & - & 47 & - & 136 & - & 153 & - \\
\hline Metaphase & & & & & & & & & & \\
\hline Total no. norm. & 74 & 33 & 27 & 18 & 52 & 37 & 97 & 85 & 53 & 53 \\
\hline C.m. & 39 & - & 9 & - & 15 & - & 12 & - & - & - \\
\hline Tetrapl. stick. & 2 & - & - & - & - & - & - & - & - & - \\
\hline Ana +telophase & & & & & & & & & & \\
\hline Total no. norm. & 47 & 41 & 77 & 77 & 56 & 53 & 54 & 40 & 23 & 23 \\
\hline C. ana. multip. & - & - & - & - & - & 2 & 1 & - & - & - \\
\hline Lagg. bridge & 5 & 1 & - & - & - & 1 & 2 & 2 & - & 一 \\
\hline & & & & & 4 hours & later & & & & \\
\hline Interphase & & & & & & & & & & \\
\hline Norm. & 5352 & & 5004 & & 5054 & & 5711 & & 5595 & \\
\hline Micro and multi. & 36 & & 27 & & - & & - & & - & \\
\hline Prophase & & & & & & & & & & \\
\hline Norm. abn. & - & - & 35 & - & 72 & - & 137 & - & 92 & - \\
\hline Metaphase & & & & & & & & & & \\
\hline Total no. norm. & 3 & 3 & 6 & 6 & 60 & 41 & 71 & 53 & 29 & 29 \\
\hline C.m. & - & - & - & & 19 & - & 18 & $=$ & - & - \\
\hline Tetrapl. stick. & - & - & - & - & - & - & - & - & - & - \\
\hline Ana + telophase & & & & & & & & & & \\
\hline Total no. norm. & 7 & 7 & 18 & 18 & 40 & 37 & 35 & 29 & 38 & 38 \\
\hline C. ana. multip. & - & - & - & - & - & - & - & - & - & - \\
\hline Lagg. bridge. & - & - & - & - & 1 & 2 & - & 6 & - & - \\
\hline
\end{tabular}


very low at the highest concentration, it was progressively raised with the decrease in the concentration. This was inversly proportional with the frequency of metaphase attained.

\section{Interaction between different concentrations of CCC and $400 \mathrm{ppm} \mathrm{IAA} \mathrm{after} 4$} hours treatment followed by 1 hour recovery

At 1 hour recovery there was an increase in anaphase frequency at all concentrations applied. This increase continued at 2 and 4 hours recovery (Table 5). At the same time there was a decrease in metaphase frequency. At all concentrations, till the minimum value was reached at 4 hours recovery. Table 5 indicates that the same number of normal and c-metaphase was found in the concentration with antagonistic effect $(4,000 \mathrm{ppm} \mathrm{CCC}+400 \mathrm{ppm}$ IAA). There was a great fall in the prophase number from 103 to 29 at this concentration (Table 5). This led to a decrease in number of total divided cells from 228 to 162 and consequently a depression in MI from 3.8 to 2.8. In general, there was a slight decrease in MI with all of the applied concentrations.

11. Interaction between different concentrations of CCC and 400 ppm IAA after 4 hours treatment followed by 2 hours recovery

Further recovery, for 2 hours showed a rapid increase in anaphase frequency (Table 5) whereas the frequency of metaphases, at the same time decreased. At all concentrations used, MI was decreased except at treatment with the lowest concentration of which MI was markedly increased from 3.2 to 5.4 above control figure (4.6). This might have been the result of an increase in the number of prophases from 75 to 136 as well as in the number of total divided cells from 184 to 278 (Table 5). The roots do a recover this could be detected since, the number of normal phases was increased and that of abnormal type was decreased.

12. Interaction between different concentrations of CCC and $400 \mathrm{ppm}$ IAA after 4 hours treatment followed by 4 hours recovery

After 4 hours recovery, there was a reduction in the total divided cells which led to a decrease in the mitotic index. There was a complete inhibition of the prophase stage, accompanied by the existance of a very few number of cells at metaphase and anaphase stages and consequently MI fell to 0.18 at the highest concentration. MI was found to increase gradually till reached the maximum value (4.8) at the lowest concentration a value which was higher than that of control (2.7). At the first two concentrations, a complete absence of abnormal divided cells has been obtained accompanied by the appearance of micronuclei. At the next concentrations, few numbers of abnormal phases at metaphases and anaphases were observed (Table 5).

\section{Discussion}

A partial antagonistic effect was reported in the present investigation as no abnormal metaphases were recorded in the combined treatment of 600 and 400 ppm IAA 
and 4,000 ppm CCC.

A confirmation of this finding was found in the result of Davidson and Macleod (1966) and many other investigators. Davidson and Macleod showed that IAA can reverse the changes that follow colchicine treatment. Mesoinositol, 6-hexachlorocyclohexane (gammexane) a widely used insecticide, has been reported by several authors to induce c-mitosis in Allium and other plant cells (D'Amato 1949, 1951, 1952, Kostoff 1938, 1940, 1948, and Northen 1950). Both the $\gamma$ and the $\alpha$ isomers have been found to be active (Carpenter and Fromageot 1950), while the first only is of use as an insecticide. Polyploidy and chromosome fragmentation have also been recorded. Gammexane is probably antagonist of a naturally occurring substances, mesoinositol, having the same steroisomeric structure as this sugar, the biological significance of which appears from its presence in many types of cells. It was not surprising that in 1948 it was announced that mesoinositol, but neither d-inositol nor sorbitol prevented, in proper concentrations, the c-mitotic activity of gammexane in Allium cepa (Chargaff, Stewart and Magasanik 1948). It was, however, more surprising and most interesting that mesoinositol was claimed to prevent also the spindle effect of colchicine. Inositol alone did not interfere with mitosis. A confirmation of these findings was found in the observation that colchicine and podophyllotoxine effects were antagonized in the egg of the sea urchin Lytechinus variegatus by glucose (Cornman 1941, 1942, 1950). The antagonism was never total; it was suggested that inositol may become changed into glucose in all cells.

In tissue cultures of rabbit heart fibroblasts, 1-ascorbic acid was found to prevent, to a certain extent, the action of colchicine (Baucher 1940, 1947). An antagonism between colchicine and soluble 'prontosil' (Sulfanilamide) has been reported in plants (Baucher 1946, 1949) but the effective concentrations of the sulfa drug were about a hundred times those colchicine, and solubility effects were unavoidable.

An extract from hearts of embryonic warm blooded animals has been reported to delay the cytotoxicity of colchicine in fibroblast and myoblast cultures. Another more recent observation is that glycosidic substances endowed with cardiotonic activity decrease the action of colchicine in tissue cultures of chick heart fibroblasts (Landschutz 1949).

It appears evident from these data that no true antagonism has yet been found between any substance and colchicine, on a molar basis, and that the only effects observed depend on the presence of substances either of unknown chemical nature or in concentrated solutions.

\section{Summary}

1. Since IAA stimulates the growth and cycocel acts as retardant for the growth of the roots we set out to determine whether is any interaction between $\mathrm{CCC}$ and IAA (indol 3-acetic acid) in the effects they produce on mitosis.

2. After 4 hours combined treatment of IAA in the previously mentioned concentrations and $12,000 \mathrm{ppm} \mathrm{CCC}$, there is a depression in the mitotic indices. Cells fixed one hour later after the above mentioned combined treatment show an 
increase in MI. On the other hand cells fixed 2 hours later showed a decrease in MI. This trend in decrease the MI continues in the following 4 hours.

3. Sticky in the highest concentrations, C-anaphases-micronuclei and multinucleated cells are the types of abnormalities which were observed after the combined treatment of IAA with $12,000 \mathrm{ppm}$ CCC.

4. The treatment of Vicia faba root cells with $400 \mathrm{ppm}$ IAA and $12,000 \mathrm{ppm}$ $\mathrm{CCC}$, causes the formation of tetraploid cells and multipolar anaphases in relatively high frequency.

5. The data from roots treated with cycocel indicates that this treatment induce alternation in the duration of mitotic cycles of cells. We have concluded that these alternations occur from changes in the numbers of cells in prophase and metaphase and the numbers of tetraploid metaphases seen in treated roots. On the other hand this change can be counteracted by supply different concentrations of IAA to a relatively moderate concentration of cycocel.

6. In addition a partial antagonistic effect was reported after treating Vicia faba roots with 600 and 400 ppm IAA and 12,000 ppm CCC. This finding agrees with the results of other investigations who concluded that antagonism between any two substances was never total.

\section{Literature}

Bauch, R. 1946. Sulfonamide als Antagonisten der polyploidisierenden Wirkung des Colchicins. Naturwiss. 33: 25-26.

- 1949. Sulfonamide und Colchicin. Ein botanischer Beitrag zum Sulfonamide-Problem. Die Pharmazie 4: 1-7.

Baucher, O. 1940. Zur Kenntnis der Mitose IX. Die Wirkung von Arsenik auf Fibrocytenkulturen. Z. Zellforsch. 30: 438-62.

- 1947. Der Eifluß von Ascorbinsäure, Araboascorbinsäure und p-Chinon auf die Colchicinwirkung. Schweiz. Z. Path. Bakter. 2: 643.

Carpenters, S. and Fromageot, C. 1950. Activite C-mitotique des isomeres et de l'hexachlorocyclohexane, avec des observations sur l'influence du mesoinositol et du mesoitophosphate de sodium. Biochem. Biophys. Acta. 5: 290-96.

Chargaff, E., Stewart, R. N. and Magasanik, B. 1948. Inhibition of mitotic poisoning by mesoinositol. Science 108: 556-58.

Cornman, I. 1941. Disruption of mitosis in Colchicum by means of colchicine. Biol. Bull. 81: 297-98.

- 1942. Susceptibility of Colchicum and Chlamydomonas to colchicine. Bot. Gaz. 104: 50-61.

- 1950. Alleviation of mitotic poisoning by glucose. Jour. Cell and Comp. Physiol. 35: 301302.

D'Amato, F. 1949. Early influence of m-inositol and sugars on gammexane induced c-mitosis. Caryologia 1 : 223-228.

- 1951. Sullapossibilita di impiego del gammesano per la produzione di poliploidi nei vegetali. Atti Convegno Genet. Agraria-Riet. pp. 427-431.

- 1952. Doesmeso-inositol inhibit the colchicine effect in the roots of Allium cepa. Arch. Inst. Pharmacodyn. 89: 409-414.

Davidson, D. and Macleald, R. D. 1966. Changes in mitotic indices in roots of Vicia faba I. Antagonistic effects of colchicine and IAA. Chromosome (Bol.) 18: 421-437.

Kabarity, A. and Khodary, S. 1974a. Interaction between the plant growth retardant (cycocel) and the plant growth stimulant indol acetic acid (IAA) I. Cytological studies upon cycocel as plant growth retardant. Beitr. Biol, Pflanzen 50: 1-19. 
- and Khodary, S. 1974b. Ditto II. Further studies upon cycocel as plant growth retardant on Vicia faba root tips. Acta biol. Acad. Sci hung. 25 (1-2): 9-24.

- and - 1974c. Ditto III. Cytological studies upon indol acetic acid. 6. Arabic scientific Congress (Cairo).

Kostoff, D. 1938. Irregular mitosis and meiosis induced by acenaphthene. Nature 141: 114445.

- 1940. A typical growth, abnormal mitosis and polyploidy induced by ethyl mercury chloride. Phytopathology 13: 91-96.

- 1948. A typical growth, abnormal mitosis, polyploidy and chromosome fragmentation induced by hexachlorocyclohexane. Nature 162: 845 .

Landschutz, C. 1949. Aufhebung der Mitosegiftwirkung des Colchicins durch herzwirksame Glykoside an Hühnerherzfibroblasten in Vitro. Naturwiss, 36: 379.

Northen, H. 1950. Alternation in the structural viscosity of protoplasm by colchicine and their relationship to c-mitosis and c-tumer formation. Amer. Jour. Biot. 37: 705-11. 